\title{
Trainee experience with capsular tension rings in Scotland-the need for structured simulation exposure to surgical adjuncts
}

\author{
Carl Mulholland ${ }^{1} \cdot$ David Lockington (i)
}

Received: 13 March 2020 / Revised: 18 March 2020 / Accepted: 18 March 2020 / Published online: 7 April 2020

(c) The Royal College of Ophthalmologists 2020

Capsular tension rings (CTRs) were first described 30 years ago as a means of maintaining capsular circular contour with the additional benefit of preventing epithelial cell invasion of the posterior capsule [1]. CTRs help redistribute tension in the setting of zonular weakness and so maintain capsule integrity during cataract surgery. Other indications for CTR use include traumatic cataract, pseudoexfoliation syndrome and systemic conditions associated with zonular weakness such as Marfan's syndrome [2]. Although their planned use can be anticipated during pre-operative evaluation, they may also be utilised due to changing intraoperative complexities.

The published literature reports that $\sim 1 \%$ of cataract operations will require the use of a CTR [3, 4]. In some countries, CTR use is related to premium IOL usage or routinely used in highly myopic patients, and this could influence reporting of use of this surgical adjunct [5]. As $\sim 42,000$ cataract operations are performed yearly within NHS Scotland, it follows that ophthalmic trainees should be aware of the indications for CTR use, and familiar with the relevant insertion techniques.

Recent evidence from the Royal College of Ophthalmologists' database has demonstrated the important role of surgical simulation (EyeSi training in first/second year trainees) in reducing complication rates and the associated costs of posterior capsule rupture [6]. In the UK, an ophthalmic trainee is deemed competent at a consultant level following completion of 350 cataract operations. Concern has previously been raised regarding the exposure and experience of managing surgical complications by senior trainees, irrespective of total cataract numbers [7].

David Lockington

davidlockington@hotmail.com

1 Tennent Institute of Ophthalmology, Gartnavel General Hospital, 1053 Great Western Road, Glasgow G12 0YN, UK
In light of this, we aimed to evaluate exposure and experience with CTR use within Scottish residency programmes via an online questionnaire (surveymonkey. com) amongst ophthalmic trainees in each respective Scottish deanery (North, East, South-East and West). Questions established respondents' surgical experience with phacoemulsification and subsequently focused on observation and use of CTRs including any prior formal training.

Thirty responses were collected from 67 trainees across Scotland (45\% response rate; 5/7 North, 2/10 East, 5/12 South-East and 18/38 West Deanery). Most respondents were within the first 3 years of training (19/30, 63\%). Fourteen trainees $(47 \%)$ had performed $<50$ phacoemulsification procedures, and eight trainees $(27 \%)$ had performed $>350$ operations (demonstrating a reasonable spread of experience in respondents). Most trainees (90\%) correctly stated zonular weakness as the primary indication for CTR use, with two junior trainees stating "don't know" (7\%).

Formal training covering the use of CTR had only been undertaken by one trainee (3\%) with the remainder having never experienced formal (dry or wet lab) CTR simulation training. Six respondents (30\%) had never observed CTR insertion and $23(77 \%)$ had never used one before. Only four trainees $(13.3 \%)$ had ever used a CTR more than once. All of those who had used a CTR were senior level trainees within the last 3 years of a 7 -year programme. However, amongst the eight senior respondents who had completed $>350$ cataract operations, two had never used a CTR and three had only ever used it once in their entire training. In addition, of these five senior respondents, four had not observed a CTR being used within the previous year.

These results demonstrate that Scottish trainee experience with CTRs is variable, with minimal formal simulated training and low levels of clinical exposure. We wish to express concern that ophthalmic training programmes can focus on complete surgical procedures performed by a 
trainee, rather than detailing surgical skills which are yet to be achieved $[7,8]$. In our study, there were eight respondents who had achieved the 350 mandatory cataract operations, and would be deemed competent as independent cataract surgeons in the UK system, yet five of these eight had minimal or no experience with the use of CTRs. We would suggest use of predictable surgical adjuncts in complex cataract surgeries should be a specific competency to be achieved within training, to ensure that new consultants are confident with adjunct use prior to finding themselves in a complex surgical predicament. We imagine that there may be similar experience gaps in ophthalmic surgical training in other deaneries and countries, and so wished to share our observations.

It follows that simulation training should be afforded to ensure familiarity with surgical techniques prior to the requirement in real-world surgery [8]. This principle should be applied to both trainees and established consultants, rather than the historic and outdated attitude of "see one, do one, teach one" [9]. Providing exposure to simulated complex scenario use for predictable surgical adjuncts should improve confidence and surgical outcomes for both the surgeon and the patient.

\section{Compliance with ethical standards}

Conflict of interest The authors declare that they have no conflict of interest.

Publisher's note Springer Nature remains neutral with regard to jurisdictional claims in published maps and institutional affiliations.

\section{References}

1. Hara T, Hara T, Yamada Y. "Equator ring" for maintenance of the completely circular contour of the capsular bag equator after cataract removal. Ophthalmic Surg. 1991;22:358-9.

2. Weber $\mathrm{CH}$, Cionni RJ. All about capsular tension rings. Curr Opin Ophthalmol. 2015;26:10-5.

3. Tribus C, Alge CS, Haritoglou C, Lackerbauer C, Kampik A, Mueller A, et al. Indications and clinical outcome of capsular tension ring (CTR) implantation: a review of 9528 cataract surgeries. Clin Ophthalmol. 2007;1:65-9.

4. Celik E, Koklu B, Dogan E, Erdogan G, Alagoz G. Indications and clinical outcomes of capsular tension ring implantation in phacoemulsification surgery at a tertiary teaching hospital: a review of 4316 cataract surgeries. J Fr Ophtalmol. 2015;38:955-9.

5. Halili I, Mutlu FM, Erdurman FC, Gündogan FC, Kilic S. Influence of capsular tension ring on posterior capsule opacification in myopic eyes. Indian J Ophthalmol. 2014;62:311-5.

6. Ferris JD, Donachie PH, Johnston RL, Barnes B, Olaitan M, Sparrow JM. Royal College of Ophthalmologists' National Ophthalmology Database study of cataract surgery: report 6 . The impact of EyeSi virtual reality training on complications rates of cataract surgery performed by first and second year trainees. Br J Ophthalmol. 2019. https://doi.org/10.1136/bjophthalmol-2018-313817.

7. Nairn J, Benjamin L, Lockington D. Comment on: 'Ophthalmology Specialist Trainee Survey in the United Kingdom'. The need to increase familiarity with the management of predictable cataract surgery complications via simulation-ensuring competence to improve confidence. Eye. 2019. https://doi.org/10.1038/s41433019-0673-y.

8. Guthrie S, Goudie C, Lockington D. Survey of Scottish ophthalmic trainees' experiences using 3-piece IOLs in cataract surgery. J Cataract Refract Surg. 2018;44:409.

9. Nicholas R, Humm G, MacLeod KE, Bathla S, Horgan A, Nally $\mathrm{DM}$, et al. Simulation in surgical training: prospective cohort study of access, attitudes and experiences of surgical trainees in the UK and Ireland. Int J Surg. 2019;67:94-100. 